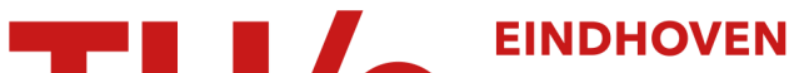 UNIVERSITY OF TECHNOLOGY
}

\section{Integrated-optics versus micro-optics : a comparison}

Citation for published version (APA):

Pennings, E. C. M., Smit, M. K., Staring, A. A. M., \& Khoe, G. D. (1996). Integrated-optics versus micro-optics : a comparison. In Integrated Photonics Research : summaries of papers presented at the topical meeting, April 29 May 2, 1996, Boston, Massachusetts (pp. 460-463). (OSA Technical Digest Series; Vol. 6).

Document status and date:

Published: 01/01/1996

\section{Document Version:}

Publisher's PDF, also known as Version of Record (includes final page, issue and volume numbers)

\section{Please check the document version of this publication:}

- A submitted manuscript is the version of the article upon submission and before peer-review. There can be important differences between the submitted version and the official published version of record. People interested in the research are advised to contact the author for the final version of the publication, or visit the $\mathrm{DOI}$ to the publisher's website.

- The final author version and the galley proof are versions of the publication after peer review.

- The final published version features the final layout of the paper including the volume, issue and page numbers.

Link to publication

\section{General rights}

Copyright and moral rights for the publications made accessible in the public portal are retained by the authors and/or other copyright owners and it is a condition of accessing publications that users recognise and abide by the legal requirements associated with these rights.

- Users may download and print one copy of any publication from the public portal for the purpose of private study or research.

- You may not further distribute the material or use it for any profit-making activity or commercial gain

- You may freely distribute the URL identifying the publication in the public portal.

If the publication is distributed under the terms of Article 25fa of the Dutch Copyright Act, indicated by the "Taverne" license above, please follow below link for the End User Agreement:

www.tue.nl/taverne

Take down policy

If you believe that this document breaches copyright please contact us at:

openaccess@tue.nl

providing details and we will investigate your claim. 


\title{
Integrated-Optics versus Micro-Optics - a Comparison
}

\author{
E.C.M. Pennings*, M.K. Smit", A.A.M. Staring ${ }^{*}$, and G.-D. Khoe ${ }^{\&}$ \\ * Philips Optoelectronics Centre, WY-61, Prof. Holstlaan 4, 5656 AA Eindhoven, The Netherlands \\ Phone: +31-40-2743037/Fax: +31-40-2743859/E-mail: epenning@natlab.research.philips.com \\ \# Delft University of Technology, Fac. of Electr. Eng., Mekelweg 4,2628CD Delft, The Netherlands \\ Phone: +31-15-2782438/Fax: +31-15-2784046/E-mail: M.K.Smit@ET.TUDelft.NL \\ \& Technical University of Eindhoven, EH-12, PO Box 513, $5600 \mathrm{MB}$ Eindhoven, The Netherlands \\ Phone: +31-40-2473452/Fax: +31-40-2455197/E-mail: G.D.Khoe@ele.tue.nl
}

\section{Introduction}

It is the purpose of this paper to assess the relative merits and prospects of integrated-optic versus microoptic devices for fiber-optic telecommunication systems. Firstly, this comparison is made from a market perspective. Then, the analogy between electronic and photonic integrated circuits is investigated. Finally, a specific comparison is made for wavelength demultiplexers for dense WDM applications. A comparison similar to this one but also including polarization-diversity hybrids can be found in Ref. 1 .

In this paper, the following classification is used:

- Fiber-based devices, such as couplers, which are exclusively made from fiber.

- Integrated-optic devices, where light is guided in planar waveguides.

- Single-component devices, such as lasers, laser amplifiers, and phase-modulators.

- Photonic integrated circuits, where a number of optical devices are monolithically integrated.

- Micro-optic devices, which rely on diffractive or reffective bulk elements such as lenses or mirrors.

- Modules, which are assembled from any of the above elements.

\section{The fiber-optic component market}

Figure 1 shows the fiber-optic component market for 1992 and 1997 in the US. A direct comparison between integrated-optic and micro-optic techniques can only be made for passive components and Fig. 1 shows that the comparison therefore applies to the smaller part of the market (15\%), since the larger part consists of active devices such as lasers and photodiodes. For passive components, the largest market segment is formed by couplers (11\%) which are almost exclusively fiber-based. This shows that the market segments captured by integrated-optic and micro-optic products are both quite small (of the order of $1 \%-2 \%$ ). The micro-optic segment consists of products such as switches, isolators/circulators, attenuators, and filters. The integrated-optic segment mainly consists of $\mathrm{LiNbO}_{3}$ switches and modulators. Another proven integrated-optic product (though active) is the DFB laser with integrated electroabsorption modulator.

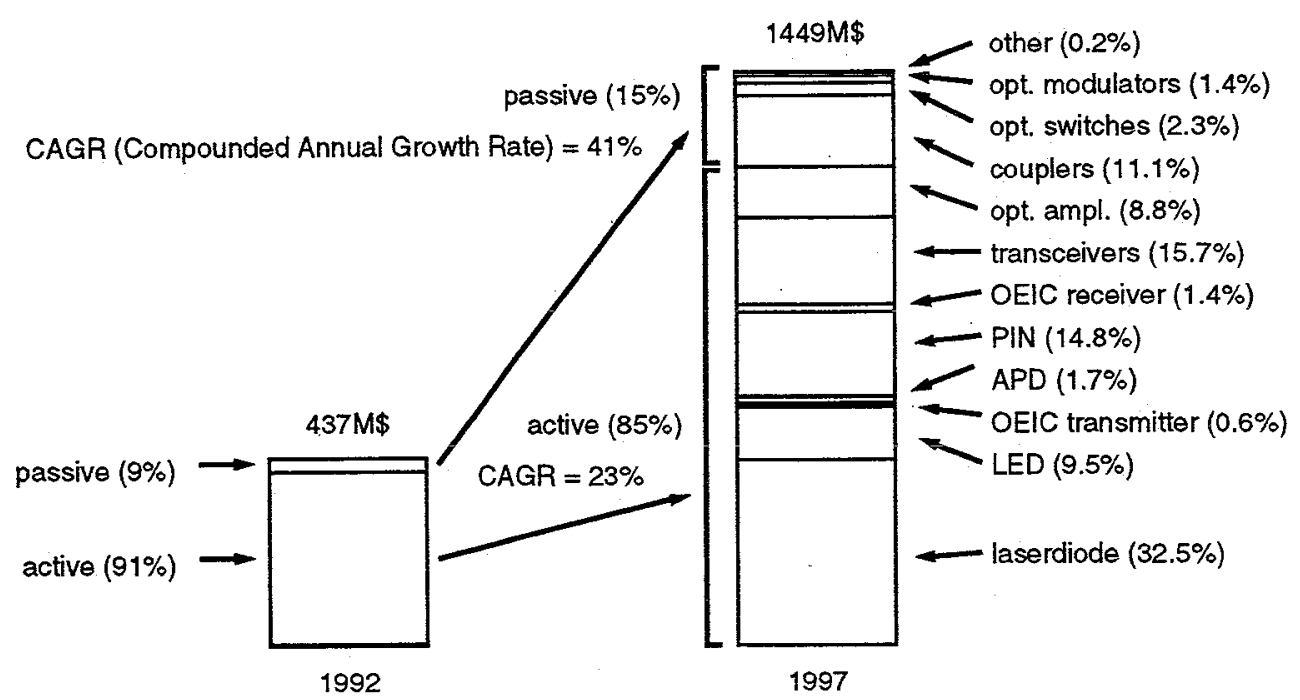

Figure 1: The 1997 US fiber-optic component market forecast (source: ElectroniCast'92). 
The market analysis shows that the demand for components with a larger degree of optical functionality has been negligible so far. This is important because the competitive edge for PIC's is precisely in integrating complex optical functionality. This situation, however, is likely to change: the market is not only growing fast (more than $25 \%$ a year), but also changing due to the rapid commercialization of WDM systems. However, the first WDM transmission systems will merely require optical devices with a single functionality, so that the demand for complex optical functionality will only increase later on, i.e. when the wavelength domain is used to realize add-drop multiplexing and cross-connecting functions.

\section{Technological considerations}

It has been argued many times that the competitive edge of photonic IC's comes from increased scale of integration plus the corresponding cost reduction. This argument is in fact based on an implicit analogy between photonic and electronic IC's. This analogy, however, has to be treated with care. Firstly, the markets for photonic and electronic IC's are very different: as was argued in the previous section, the demand for complex optical functionality is still in its infancy. Secondly, there are several technical reasons why photonic and electronic IC's are quite different:

Packaging is much more difficult for photonic than for electronic IC's. Packaging related issues are the fiber-chip coupling problem which leads to the use of tapers and lenses, the influence of reflections and the accompanying use of isolators, and temperature sensitivity which can necessitate Peltier coolers and thermistors. It is important to notice that these packaging issues form, on one hand, the major economic incentive for integration, but that they, at the same time, form a technical obstacle against integration.

The scale of integration seen in electronic IC's is directly related to intrinsic on chip amplification and feedback which allow for accurate performance control and thus for the ability to cascade a large number of components. So far, optical feedback is not feasible in photonic IC's and integrated optical amplifiers are in their infancy. Even more important is that the characteristic size of the building blocks for photonic and electronic IC's differ by at least two to three orders of magnitude. Lastly, whereas electronic IC's contain many duplicates of a small set of building blocks, most photonic IC's integrate a number of very different elements. The accompanying problem of optimizing the performance of each individual subelement complicates the design and leads to compromises in performance.

As a result, photonic IC's will follow their own rule of economy, different from electronic IC's, and will reach a more limited scale of integration. In order to reach that limit and speed up commercialization, additional effort will be required to reduce packaging costs, incorporate on-chip amplification, reduce component size, and to develop improved processes and fabrication-tolerant components.

\section{Wavelength demultiplexers for dense WDM applications: a comparison}

In this section, a specific comparison is made for a key component in OFDM networks, i.e. the wavelength demultiplexer for dense WDM applications. The development of these demultiplexers is shown in Fig. 2.

Fiber-based: The lack of fiber-based demultiplexers in Fig. 2 illustrates the unsuitability of fibers to demultiplex many closely spaced wavelengths simultaneously. Fibers are, on the other hand, very suitable to demultiplex two widely spaced wavelengths (i.e. duplexers), which are typically used for two-channel transmission systems (e.g. $1.31 / 1.55 \mu \mathrm{m}$ ), or in EDFA's $(0.98 / 1.55 \mu \mathrm{m}$ and $1.48 / 1.55 \mu \mathrm{m}$ ). It is important to notice that duplexers form more than $90 \%$ of the demultiplexer market and are almost entirely fiber-based.

Modules: Fibers can, of course, be used in combination with filters to realize wavelength demultiplexers for dense WDM. These filters can be placed in series (cascaded) or in parallel by using a fiber splitter. Popular filters are the (fixed) interference filter ${ }^{2}$ and the tunable (fiber) Fabry-Pérot filter.

Micro-optics: Fig. 2 shows that much of the work on micro-optical demultiplexers was already published in the early eighties ${ }^{3-6}$ when MM fibers were used with wavelengths of $\lambda=700-900 \mathrm{~nm}$. The subsequent reduction of interest was due to the shift of focus to coherent detection schemes. In the late eighties, when interest in WDM revived, work on micro-optical demultiplexers continued $d^{7-11}$ and several earlier designs were commercialized. Micro-optical wavelength demultiplexers can be divided into the cascaded interference filter type and the grating-based type. Recently, the phased array design, which is typical for integrated optics, has also been realized in micro-optics ${ }^{12}$. 


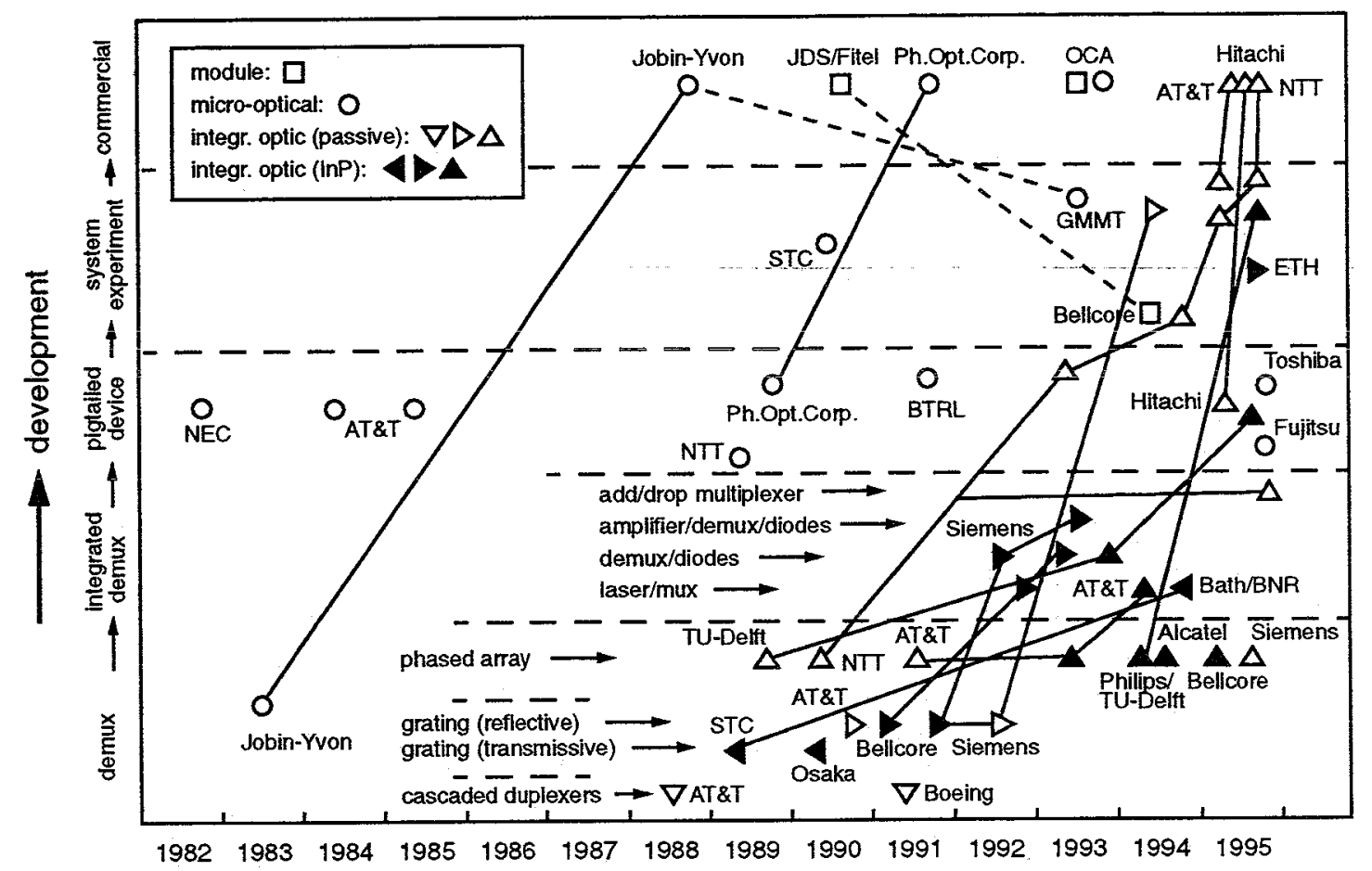

Figure 2. Overview of reported wavelength demultiplexers and their development in time.

Integrated optic: The first integrated optic demultiplexers appeared in the late eighties and relied on cascaded duplexers ${ }^{13-14}$. Soon afterward, planar versions of the micro-optic grating based demultiplexer were reported ${ }^{15-20,21-22}$. An alternative design is the phased array (PHASAR) or arrayed waveguide grating (AWG) ${ }^{23-30}$. This design has recently gained in importance due to superior performance and ease of processing. Fig. 2 shows how integrated-optic demultiplexers have subsequently been integrated into more complex PIC's (such as lasers ${ }^{31-33}$, receivers r $^{34-37,38}$, and an add/drop multiplexer ${ }^{39}$ ) and how they have been used in various system experiments ${ }^{40,41-45}$. It seems that this development is accelerating which is, for example, demonstrated by the rapid commercialization ${ }^{46}$ of the Si-based demultiplexers.

Discussion and conclusion. The performance of a variety of commercial demultiplexers is compared in Table 1. The splitter plus filter configuration is rather popular due to its simplicity and tunability, but it poses an intrinsic splitter $\operatorname{loss}$ of $10 \cdot \log (\mathrm{N})$ and may show unwanted back-reflections. Fixed demultiplexers will gain in importance, as soon as WDM channels have been standardized. For cascaded filters, the loss increases proportional to number of channels, which limits its suitability to $4-8$ channels. Micro-optic demultiplexers offer proven reliability in addition to excellent performance in terms of number of

Table 1: Overview of performance of commercial wavelength demultiplexers.

\begin{tabular}{|c|c|c|c|c|c|c|c|c|c|}
\hline Technique & Type & $\mathrm{N}$ & $\begin{array}{c}\Delta \lambda \\
(\mathrm{nm})\end{array}$ & $\begin{array}{l}\text { Ins.Loss } \\
\text { (dB) }\end{array}$ & $\begin{array}{c}\text { Ret.Loss } \\
\text { (dB) }\end{array}$ & $\begin{array}{l}X-\text { talk } \\
(-\mathrm{dB})\end{array}$ & $\begin{array}{c}\text { Drift } \\
\left(\mathrm{nm} /{ }^{\circ} \mathrm{C}\right)\end{array}$ & $\begin{array}{l}\text { Pol.Dep. } \\
\text { (dB) }\end{array}$ & Vendor \\
\hline \multirow{3}{*}{ Module } & \multirow{2}{*}{$\begin{array}{l}\text { Splitter + } \\
\text { FFP-filter }\end{array}$} & & & $<1.5-2.5$ & $?$ & $?$ & Act. tuning & $<0.5$ & Micron Optics \\
\hline & & & & $<4$ & $>22-40$ & $?$ & Act. tuning & $?$ & Queensgate \\
\hline & Cascaded filters & & & $<1.5$ & $>40-55$ & $>15$ & 0.004 & $?$ & OCA \\
\hline \multirow{2}{*}{$\begin{array}{l}\text { Micro- } \\
\text { Optic }\end{array}$} & Cascaded filter & $4-8$ & 1.6 & $<3-4$ & $>40-55$ & $>30$ & 0.004 & $<0.1$ & OCA \\
\hline & Grating & $4-41$ & $1-16$ & $<3-5$ & $?$ & $>30-55$ & $0.02-0.004$ & $?$ & Jobin-Yvon \\
\hline \multirow{3}{*}{$\begin{array}{l}\text { Integr.- } \\
\text { Optic }\end{array}$} & \multirow{3}{*}{$\begin{array}{c}\text { PHASAR } \\
\text { (passive) }\end{array}$} & 8 & $?$ & $<10$ & $>25$ & $>20$ & $?$ & $<1$ & Hitachi \\
\hline & & 8 & 1.61 & $<10$ & $>30$ & $>20$ & 0.01 (tuning) & $?$ & AT\&T \\
\hline & & $4-32$ & $0.8-2$ & $<6-7$ & $>40$ & $>20-22$ & Peltier/NTC & $<0.3$ & NTT \\
\hline
\end{tabular}


channels, insertion loss, cross-talk, polarization-dependence and thermal stability ${ }^{47}$. Integrated optic demultiplexers, especially the phased array type, have seen an enormous development and the recently commercialized Si-based demultiplexers show a very competitive performance. The performance of these commercial versions can, however, not yet match that of micro-optic versions. This leads us to conclude that the real breakthrough for integrated optics has to be expected when both technology and market are ready for photonic IC's with increased functionality due to a larger scale of integration.

\section{References}

[1] E.C.M. Pennings et al., Proc. MOC'95, (Oct. 18-20, 1995, Hiroshima, Japan), paper J1.

[2] L. Eskildsen et al., IEEE Photon. Technol. Lett., vol. 6, no. 11, pp. 1321-1323, 1994.

[3] M. Seki et al., Electron. Lett., vol. 18, no. 6, pp. 257-258, 1982.

[4] J.P. Laude et al., Proc. $9^{\text {th }}$ ECOC '83, (Oct. 23-26, 1983, Geneva, Switzerland), pp. 417-420.

[5] J. Hegarty et al., Electron. Lett., vol. 20, no. 17, pp. 685-686, 1984.

[6] J. Lipson et al., J. Lightw. Technol., vol. 3, no. 5, pp. 1159-1162, 1985.

[7] Y. Fujii et al., Appl. Opt., vol. 28, no. 7, pp: 1305-1308, 1989.

[8] - B. Moslehi et al., Opt. Lett., vol. 14, no. 19, pp. 1088-1090, 1989.

[9] G.J. Cannell et al., IEEE J. Sel. Areas. in Comm., vol. 8, no. 6, pp. 1141-1145, 1990.

[10] D.R. Wisely et al., Electron. Lett., vol. 27, no. 6, pp. 520-521, 1991.

111] K.J. Hood et al., J. Lightw. Technol., vol. 11, no. 5/6, pp. 680-687, 1993.

[12] M. Shirasaki, Proc. MOC'95, (Oct. 18-20, 1995, Hiroshima, Japan), paper PD3.

[13] B.H. Verbeek et al., J. Lightw. Technol., vol. 6, no. 6, pp. 1011-1015, 1988.

[14] J.P. Lin et al., Opt. Lett., vol. 16, no. 7, pp. 473-475, 1991.

[15] M. Gibbon et al., Electron. Lett., vol. 25, no. 21, pp. 1441-1442, 1989.

[16] S. Ura et al., Appl. Opt., vol. 29, no. 9, pp. 1369-1373, 1990.

[17] C.H. Henry et al., J. Lightw. Technol., vol. 8, no. 5, pp. 748-755, 1990.

[18] J.B.D. Soole et al., Electron. Lett., vol. 27, no. 2, pp. 132-134, 1991.

[19] C. Cremer et al., Appl. Phys. Lett., pp. 627-629, 1991

[20] P.C. Clemens et al., IEEE Photon. Technol. Lett., vol. 4, no. 8, pp. 886-887, 1992.

[21] J.G. Bauer et al., Proc. ECOC'94 (Sept. 25-29, 1994, Florence, Italy), pp.751-754.

[22] E. Gini et al., Proc. ECOC'95, (Sept. 17-21, 1995, Brussels, Belgium) pp. 207-210.

[23] A.R. Vellekoop et al., Proc. ECOISA'89, (Sept. 25-28, 1989, Amsterdam, The Netherlands), paper D3.

[24] H. Takahashi et al., Electron. Lett., vol. 26, no. 2, pp. 87-88, 1990.

[25] C. Dragone, IEEE Photon. Technol. Lett., vol. 3, no. 10, pp. 896-899, 1991.

[26] M. Zirngibl et al., Electron. Lett., vol. 29, no. 2, pp. 201-202, 1993.

[27] B.H. Verbeek et al., Proc. OFC'94, (Febr. 20-25, 1994, San Jose, USA), post-deadline paper PDP13.

[28] H. Bissessur et al., Electron. Lett., vol. 30, no. 4, pp. 336-337, 1994.

[29] M.R. Amersfoort et al., Proc. IPR'95, (Febr. 23-25, 1995, Dana Point, USA), post-deadline paper PD3.

[30] P.C. Clemens et al., Proc. $7^{\text {th }}$ ECIO'95, (April 3-6, 1995, Delft, The Netherlands), pp. 505-508.

[31] J.B.D. Soole et al., Electron. Lett., vol. 28, no. 19, pp. 1805-1807, 1992.

[32] M. Zirngibl et al., Electron. Lett., vol. 30, no. 9, pp. 701-102, 1994.

[33] M. Asghari et al., Electron. Lett., vol. 30, no. 20, pp. 1674-1675, 1994.

[34] C. Cremer et al., IEEE Photon. Technol. Lett., vol. 4, no. 1, pp. 108-110, 1992.

[35] J.B.D. Soole et al., Electron. Lett., vol. 29, no. 6, pp. 558-560, 1993.

[36] C. Cremer et al., Proc. ECIO'93, (April 18-22, 1993, Neuchâtel, Switzerland), p. 2-10.

[37] M.R. Amersfoort et al., Proc. ECOC'93, (Sept. 12-16, 1993, Montreux, Switzerland), post-deadline, pp. 49-52.

[38] C.A.M. Steenbergen et al., Proc. ECOC'95, (Sept. 17-21, 1995, Brussels, Belgium) pp. 211-214.

[39] K. Okamoto et al., Proc. OFC'95, (Febr. 26 - Mar. 3, 1995, San Diego, USA), paper PD10.

[40] Y. Tachikawa et al., Electron. Lett., vol. 29, no. 24, pp. 2133-2134, 1993.

[41] S. Suzuki et al., Electron. Lett., vol. 30, no. 13, pp. 1091-1092, 1994.

[42] O. Ishida et al., Proc. OFC'95, (Febr. 26 - Mar. 3, 1995, San Diego, USA), paper PD9.

[43] B.R. Hemenway et al., Proc. OFC'95, (Febr. 26 - Mar. 3, 1995, San Diego, USA), paper PD8.

[44] L.H. Spiekman et al., Proc. ECOC'95, (Sept. 17-21, 1995, Brussels, Belgium) pp. 1055-1058.

[45] K. Oda et al., Proc. ECOC'95, (Sept. 17-21, 1995, Brussels, Belgium) pp. 59-62

[46] H. Uetsuka et al., Proc. OFC'95, (Febr. 26 - Mar. 3, 1995, San Diego, USA), paper TuO7.

[47] M. Miyachi et al., Proc. ECOC'95, (Sept. 17-21, 1995, Brussels, Belgium) pp. 67-70. 